\title{
Online Evaluation System of Power Grid Efficiency
}

\author{
Chen Weihua ${ }^{1,2^{*}}$, Shan Renzhong ${ }^{1,2}$, Bai Cuifen ${ }^{1,2}$, and Zhang Youdong ${ }^{1,2}$ \\ ${ }^{1}$ School of Mechanical and Electrical Engineering, North China Institute of Science and Technology, China \\ ${ }^{2}$ Hebei Key Laboratory of Safety Monitoring of Mining Equipment, North China Institute of Science and Technology, China
}

\begin{abstract}
Transmission network is an important part of power system. The operation efficiency of transmission network is one of the important indexes of power system. At present, there is still much room to improve the efficiency of China's transmission network. There is a lack of a suitable system to evaluate the operation efficiency of transmission network. In order to effectively evaluate the efficiency of transmission network, this paper establishes the evaluation index system of transmission network operation efficiency and applies it to the actual power system. The test results verify the feasibility of the proposed index system.
\end{abstract}

\section{Introduction}

Transmission network is of the characteristics of large scale, many components and complex dispatching operation. The characteristics and situations of different development stages of transmission network are different, so the evaluation index and method will be focused on according to the evaluation object. Based on the national conditions, the principle and idea of index selection should be determined by the characteristics of power grid. The transmission network operation evaluation index should be classified to establish the evaluation framework. It is conducive to the next step of transmission network evaluation work. It is of the pertinence, timeliness and operability [1-4].

Online evaluation technology has been a significant development. Online evaluation technology also meets new challenges. The use of advanced measurement and monitoring equipment and the large demand for information exchange put forward new requirements for sensing technology and big data processing technology. In the process of system operation, protection, maintenance and life cycle management, new measurement parameters, network information, communication technology and related new algorithms are needed. Identification of exchange data and its related requirements, such as data reliability, security, etc. Fault recovery and transfer planning method. Network security and access control, including network security, information security and other issues. The growth of DC technology and power electronics application at various voltage levels and its impact on power quality, system control, system safety and system standardization. The traditional circuit theory cannot be directly used, so more research on new technologies is needed. The increase of line capacity, the use of overhead, underground and underwater facilities and their impact on the technical performance and reliability of the network. The technology of improving the transmission capacity of existing overhead lines, including replacing high temperature resistant wires, re tightening existing overhead line wires, improving voltage level and real-time monitoring. The $\mathrm{AC}$ is converted into DC line, the AC-DC hybrid transmission is considered, and the tight arrangement and aesthetics of overhead lines are considered. The overload capacity and thermal transient calculation of underground system are considered. And the influence on the design standard of underground part is considered.

This paper summarizes the Principles of establishing evaluation framework. The Basic structure of the evaluation framework is analysed. The control mode of power system is put forward. The actual data of two regional power systems are calculated. The test results verify the feasibility of the proposed index system.

\section{Principles of establishing evaluation framework}

Power grid is an important power infrastructure to meet the social and economic development. China's transmission network is in a period of rapid development. Therefore, at this stage, the evaluation of transmission network operation will focus on whether the speed and efficiency of power grid development meet the needs of social and economic development. The openness, sustainable development and tolerance of industrial layout and development of transmission network fairness are the important contents of the evaluation [5-8].

The establishment of evaluation framework should not only fully sort out and absorb the existing mature evaluation indexes of power grid, but also keep pace with the times, innovate and improve to meet the requirements of power grid development. The evaluation framework should adapt to the situation of transmission

\footnotetext{
* Corresponding author: cwhwc@163.com
} 
and distribution integration of China's power grid, fully consider the characteristics of China's economic and social development, transmission network scale and structure, and follow the principles of feasibility, completeness, intuition, independence and comparability.

\section{Basic structure of the evaluation framework}

According to the above requirements, the operation evaluation framework of transmission network developed at this stage includes the comprehensive evaluation of transmission network development, efficiency and benefit, as well as safety and reliability [9-10]. The evaluation index is divided into three categories: development index, benefit index and safety index. Among them, the development index mainly reflects the length of transmission lines, transformation capacity, grid density and other aspects of China's power grid. The benefit index mainly reflects the investment and operation benefits of China's power grid, including transmission line loss, transformation utilization efficiency, transmission channel utilization rate, incremental power transmission capacity per unit, grid investment and renewable energy generation acceptance, etc. The safety index mainly reflects the investment and operation benefits of China's power grid. To reflect the reliability of China's power grid operation, it mainly includes transmission system "n-1" passing rate, load limiting rate, system fault load limiting probability, system fault load limiting severity and so on..

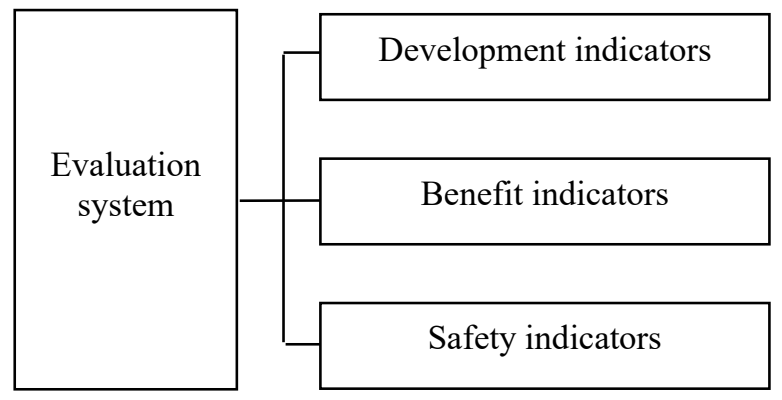

Fig. 1. Evaluation system

\subsection{Development indicators}

Development indicators include growth rate of line length, Growth rate of substation capacity and grid density.

(1) Growth rate of line length

This index reflects the speed of transmission line scale change. The growth rate of the sum of AC and DC line lengths of $330, \pm 400, \pm 500,500, \pm 660,750, \pm 800$ and $1000 \mathrm{kV}$ voltage levels is calculated respectively.

(2) Growth rate of substation capacity

This index reflects the speed of the change of the capacity of transmission network. The growth rate of the sum of the substation capacity of $330, \pm 400, \pm 500,500$, $\pm 660,750, \pm 800$ and $1000 \mathrm{kV}$ voltage levels is calculated respectively.

(3) Grid density
This index reflects the density of transmission network per unit land area. The sum of AC and DC line length and corresponding transformer capacity of $330, \pm$ $400, \pm 500,500, \pm 660,750, \pm 800$ and $1000 \mathrm{kV}$ voltage level in unit land area is calculated respectively.

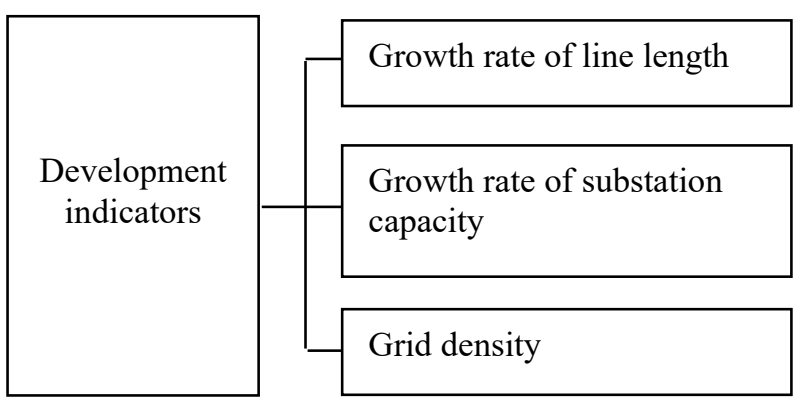

Fig. 2. Development indicators

\subsection{Benefit indicators}

Benefit indicators include growth rate of line length, Growth rate of substation capacity and grid density.

(1) Transmission line loss rate

This index reflects the degree of power consumption and loss in the production process of power transmission enterprises. It is an important efficiency index reflecting the operation level of power transmission enterprises. Data of electric quantity of each gateway of transmission line and data of transmission network structure parameters and typical operation mode are needed.

(2) Utilization rate of substation

This index reflects the relationship between the power supply capacity of a substation or a regional stepdown transformer and the maximum actual capacity of the network. It is the adequacy index of the power supply capacity of the main network. Data of the actual operation of the maximum power grid and data of stepdown substation capacity are needed.

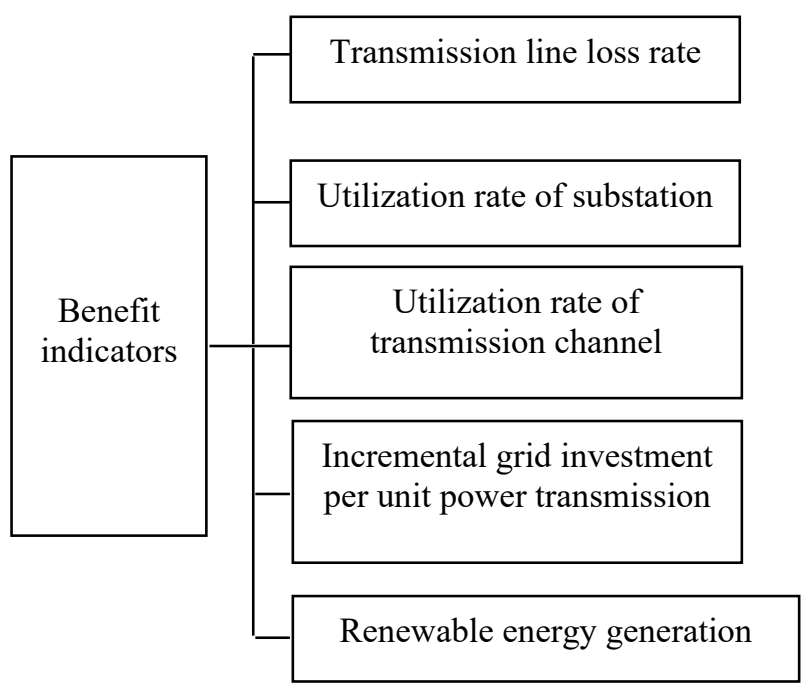

Fig. 3. Benefit indicators

(3) Utilization rate of transmission channel

This index reflects the utilization efficiency of the main AC transmission channels in the transmission network. Transmission channel is an important part of 
AC transmission network. Its efficiency can directly reflect the operation efficiency of $\mathrm{AC}$ power grid and directly related to the investment income of $\mathrm{AC}$ power grid. Data of annual transmission capacity, conductor type and planned maintenance hours of AC transmission channel are needed.

(4) Incremental grid investment per unit power transmission

This index reflects the benefit of incremental investment in transmission network. The increase of the transmission capacity of the transmission network is closely related to the expansion of the scale of the transmission network, the renewal of equipment, the upgrading of technology and other factors, which are related to the investment of the power grid. The incremental grid investment per unit of power transmission quantifies the marginal investment cost of each additional unit of power transmission. Data of the investment of power transmission network in time interval and the added value of power transmission in time interval are needed.

(5) Renewable energy generation

This index reflects the scale of hydropower, wind power and other renewable energy power generation. Classified statistics of renewable energy power generation are needed.

\subsection{Safety indicators}

Safety indicators include N-1 pass rate, severe load limitation of power grid, theoretical fault load limiting probability and theoretical fault load limiting severity.

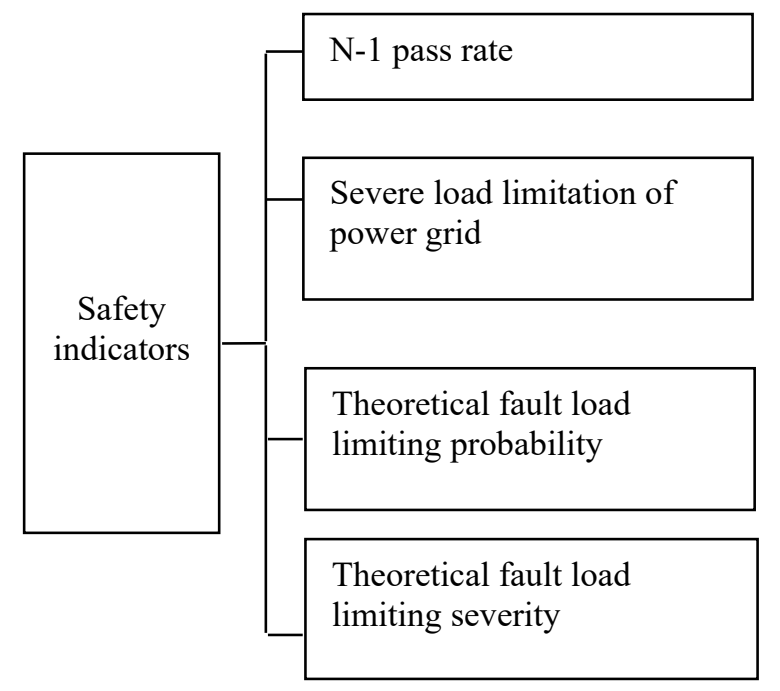

Fig. 4. Safety indicators

(1) N-1 pass rate

This index reflects the ability of transmission network to maintain safe and stable operation in case of N-1 fault. Generally speaking, the transmission network is designed and constructed according to the principle of "n-1" without load loss. However, in actual operation, due to the increase of power load, considering the planned maintenance and special start-up arrangement of generator units, there will be individual "n-1" supply restriction. Data of transmission network structure and electrical parameters, power flow data of typical operation mode, planned maintenance arrangement are needed.

(2) Severe load limitation of power grid

This index reflects the severity of load limiting due to insufficient power supply capacity of transmission network or system fault. Due to the insufficient installed capacity of the system and generating capacity of the unit, the power load limit is not within the statistical range. Data of limited power supply are needed.

(3) Theoretical fault load limiting probability

Through theoretical calculation, the probability of load limitation due to fault is reflected by this index. Data of transmission network structure parameters, typical operation mode, equipment failure rate are needed.

(4) Theoretical fault load limiting severity

This index reflects the proportion of the load limited due to system fault in the maximum power load of the system in a period of time. Data of transmission network structure parameters, typical operation mode, equipment failure rate are needed. This index is calculated by Monte Carlo method.

\section{Case study}

In this paper, the actual data of two regional power systems are calculated, as shown in the figure below. A region is located in the hinterland of Southwest China inland area. It is a transportation hub in Southwest China and an important part of the Yangtze River economic belt. A region is the first national comprehensive test area of big data, a world-famous mountain tourism destination and a large mountain tourism province, a national ecological civilization test area and an open inland economic test area. Region B is located in the north of China, with a long and narrow terrain stretching from northeast to southwest. The whole region is basically a plateau type geomorphic area, covering plateau, mountain, hill, plain, desert, river, lake and other landforms. The climate is mainly temperate continental climate, and it crosses the yellow River, Erguna River, Nenjiang River and Xiliao River.

Table 1. Power system emergency response

\begin{tabular}{|c|c|c|}
\hline & $\mathrm{A}$ & $\mathrm{B}$ \\
\hline Growth rate of line length & $21.7 \%$ & $13.4 \%$ \\
\hline $\begin{array}{c}\text { Growth rate of substation } \\
\text { capacity }\end{array}$ & $24.10 \%$ & $9.50 \%$ \\
\hline $\begin{array}{c}\text { Grid density } \\
\text { Transmission line loss rate }\end{array}$ & $8 \%$ & 30 \\
\hline $\begin{array}{c}\text { Utilization rate of substation } \\
\text { Utilization rate of transmission } \\
\text { channel }\end{array}$ & $83 \%$ & $79 \%$ \\
\hline \begin{tabular}{c} 
Can \\
\hline
\end{tabular} & $63 \%$ \\
\hline
\end{tabular}




\begin{tabular}{|c|c|c|}
\hline $\begin{array}{c}\text { Incremental grid investment } \\
\text { per unit power transmission }\end{array}$ & 424 & 579 \\
\hline Renewable energy generation & 76 & 12 \\
\hline N-1 pass rate & $100 \%$ & $100 \%$ \\
\hline $\begin{array}{c}\text { Severe load limitation of power } \\
\text { grid }\end{array}$ & $0.10 \%$ & $0.20 \%$ \\
\hline $\begin{array}{c}\text { Theoretical fault load limiting } \\
\text { probability }\end{array}$ & $0.01 \%$ & $0.01 \%$ \\
\hline $\begin{array}{c}\text { Theoretical fault load limiting } \\
\text { severity }\end{array}$ & 5 & 7 \\
\hline
\end{tabular}

\section{Conclusion}

Power grid is the link between power supply and users. It is the bridge of power resource allocation. And it also is the trading platform of power market and the transmission intermediary of social interests.

Further improve the planning mechanism and realize the closed-loop management. Improve the scientificity of power planning. The coordination of power grid planning and power planning should be enhanced. And the seriousness of power planning implementation should be strengthened. It is necessary to strengthen the supervision and evaluation of the implementation of power planning. A closed-loop management mechanism of power planning, construction, operation and evaluation should be established. And better consideration should be given to the safety and economy of power development.

The construction of power grid should be strengthened. And the investment in the construction of distribution network should be increased.

On the basis of ensuring security and stability, give full play to the potential of existing power grid equipment. The operation level of power grid should be improved. Power grid congestion should be solved. And power grid transmission capacity should be improved. It is necessary to give better consideration to the security and economy of power grid operation.

The supervision of power dispatching and power grid operation should be strengthened. A scientific and reasonable evaluation index system of power grid operation should be studied and formulated. An evaluation mechanism of power grid operation should be established. The supervision of power transmission and transformation project operation effectiveness should be strengthened. And promote power grid enterprises to improve power grid operation efficiency and investment efficiency. We should strengthen the supervision of transmission and distribution cost, promote the reform of power market. Making power grid develop healthily along the road guided by the scientific outlook on development.

The electric power regulation system should be revised and improved as soon as possible. According to the current situation of the power industry management system, we should pay close attention to revising the norms and standards affecting the power grid. So as to fundamentally guarantee and promote the scientific, safe and efficient development of the power grid.

\section{Acknowledgements}

The acknowledgements: this paper is supported by the Fundamental Research Funds for the Central Universities (3142020014) and the Fundamental Research Funds for the Central Universities (3142019055).

\section{References}

1. Ren Dongming, Xie Xuxuan, Liu Jian. To promote energy production and consumption revolution in China Energy of China, 35, 6-10(2013).

2. Dong Zhaoyang, Zhao junhua, Wen Fushuan, Xue Yusheng. From Smart Grid to Energy Internet: Basic Concept and Research Framework. Automation of Electric Power Systems, 39, 111(2014).

3. Tian Shiming, Luan Wenpeng, Zhang Dongxia, et al. Technical Forms and Key Technologies on Energy Internet. Proceedings of the CSEE, 35, 34823494(2015).

4. $\mathrm{Xu}$ Wei. Participation mode of large-scale Jiuquan wind power farm in Gansu province to electricity market and its utilization scheme. Power System Technology, 34, 71-77(2010).

5. Yao Liangzhong, Wu Jing, Wang Zhibing, et al. Pattern analysis of future HVDC grid development. Proceedings of the CSEE, 34, 6007-6020(2014).

6. Liu Zhenya, Shu Yinbiao, Zhang Wenliang, et al. Study on voltage class series for HVDC transmission system. Proceedings of the CSEE, 28, $1-8(2008)$.

7. Hu Xuehao. Smart grid: a development trend of future power grid. Power System Technology, 33, 15(2009).

8. Wang Yimin. Research framework of technical standard system of strong \& smart grid. Automation of Electric Power Systems, 34, 1-6(2010).

9. Luo Haiyang. Chaotic forecasting method of shortterm wind speed in wind farm. Power System Technology, 33, 67-71(2016).

10. Su Peng. Determination of optimal spinning reserve of power grid containing wind. Power System Technology, 34, 158-162(2010).

11. Wang Mingjun. Smart grid and smart energy resource grid. Power System Technology, 34, 15(2010). 